\section{Mentally disabled research subjects 'need protection'}

[WASHINGTON] When the US National Bioethics Advisory Commission (NBAC) convenes again on Sunday (19 October), it will wrestle with a difficult matter on which it is due to report by January. The commission's human subjects subcommittee, which meets the same day, is charged with working out how to provide adequate protection for mentally disabled research subjects, for whom no specific protection exists under federal regulations.

Two national commissions have recommended that the government adopts such protection - which already exists for pregnant women, fetuses, prisoners and children. But an early effort to introduce it was abandoned after an outcry from researchers. Patients' advocates say this has led to widespread abuses, and are calling for stringent government measures to be adopted.

"Highly speculative, relapse-producing experiments may have served the interests of investigators, but they undermined the best medical interests of the subjects," says Vera Hassner Sharav, director of Citizens for Responsible Care in Psychiatry and Research.

The seriousness of the advocates' cause was brought home to members of NBAC's human subjects subcommittee at a meeting last month where they heard harrowing testimony from former research subjects. They alleged cursory, inadequate or nonexistent informed-consent procedures, abrupt withdrawal of medication, inducing psychosis, and restraint in locked wards.

Although several cases presented at the meeting involved private facilities, others involved research financed by the National Institute of Mental Health (NIMH), including one study at the institute itself in Bethesda, Maryland. There, a former subject said, he was presented with a notebook of consent forms three to four inches thick. "I was given no opportunity to read them [or] consider them. The doc turned the pages and I signed."

Such a process "could not in a million years be characterized as informed voluntary consent," said Alexander Capron, an NBAC member who is a bioethicist at the University of Southern California.

Rex Cowdry, acting deputy director of NIMH, said the institute took the allegations "seriously". He said the institute "is already actively involved in a broad examination of how we can assure that our research participants are well-informed".

But some NBAC members said it was important that protection for subjects should not cripple research. "It also can be unethical not to do research," said Arturo Brito, a paediatrician at the University of Miami. M. W.

\title{
Row over alternative medicine's status at NIH
}

[WASHINGTON] Six years after it was set up on the recommendation of a congressional committee, the Office of Alternative Medicine (OAM) at the US National Institutes of Health (NIH) is again under close public scrutiny, this time over the proposal that it should be elevated to a grant-giving centre.

Senator Tom Harkin (Democrat, Iowa), who as head of a key subcommittee responsible for funding the NIH was instrumental in OAM's creation in 1991, is now suggesting that the $\$ 12.5$ million office be upgraded to a National Center for Complementary and Alternative Medicine Research.

But the proposal has run into stiff opposition from parts of the scientific establishment who, deeply sceptical of many of alternative medicine's claims, want OAM abolished. At a hearing last week of the Public Health Subcommittee of the Senate Labor and Human Resources Committee, the critics' views received close attention.

Harkin believes that NIH bias against the OAM has rendered it nearly ineffectual. OAM was created to investigate and validate alternative therapies, but hasn't "investigated and validated one darn thing" and needs the institutional power to do so, he said.

OAM grants must at present be funded in collaboration with other institutes. According to Harkin, this means that peerreviewers with no interest in alternative medicine give proposals short shrift.

He pointed as evidence to budget figures from 1996, when an estimated $\$ 43.7$ million of NIH's \$11.9 billion budget was spent on alternative medicine research. Harkin charged that NIH's director, Harold Varmus, has requested that OAM's own budget for this year be cut by 40 per cent, to $\$ 7.5$ million.

"What signal does that send about the interest of the head of NIH" in alternative research, Harkin demanded? He says the solution is to give OAM the power of an NIH centre, with authority to recruit its own peerreviewers and award its own grants.

But Bill Frist (Republican, Tennessee), a cardiac surgeon and the subcommittee chairman, said scientists fear "you are going to get unsafe, ineffective products, therapies, procedures" if people who believe in alternative medicine are made peer-reviewers.

OAM's critics argue that alternative therapies should be examined by peer-reviewers within NIH's existing institutes. Frist has received a letter from Nobel laureates, including Paul Berg of Stanford University and Allan Bromley of Yale, urging that OAM's effectiveness be rigorously scrutinized before an upgrade is even considered.

"To elevate the Office of Alternative Med-

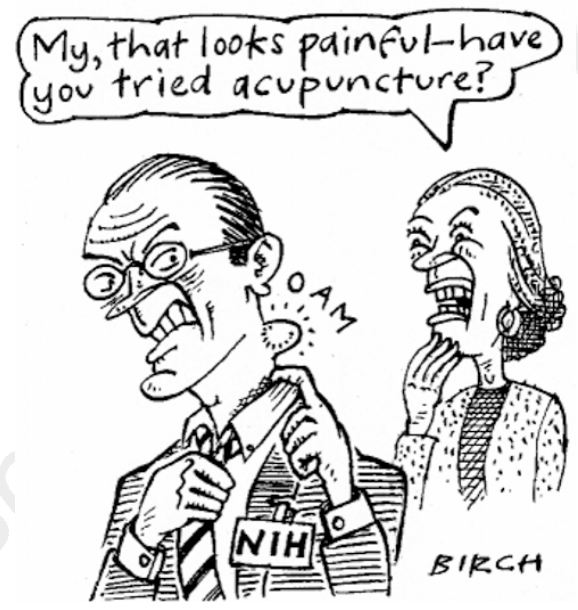

icine to the status of a national centre without first examining its strengths and weaknesses would risk amplifying existing problems," the laureates wrote. Bromley, science adviser to former president George Bush, has elsewhere accused OAM of lending credibility to practices that "more clearly resemble witchcraft than medicine".

One witness at the hearing, Robert Rich, vice-president at Baylor College of Medicine in Houston, Texas, testified on behalf of the Association of American Medical Colleges that upgrading OAM to a centre would "at least double" its administrative costs. "Use the experience and talent of the existing institutes" to evaluate research on alternative therapies, he said.

But another witness, James Gordon, the director of the Center for Mind-Body Medicine at Georgetown University in Washington DC, and the first chairman of the advisory council at OAM, said the public would be far better served by an expanded OAM.

Gordon called the office's current budget and staff size "completely inadequate", and urged a budget of \$100 million-\$150 million. He said that, among 125 reviewers on NIH's 26 standing review committees, not one had a degree or licence in alternative medicine fields such as chiropractice and acupuncture.

Whatever the scientists' views, it is clear that alternative therapies are intensely interesting to the US public. One-third of respondents in a 1993 study in the New England Journal of Medicine said they had used an alternative therapy in the previous year. And OAM receives about 1,200 calls from the public each month, a figure at least equal to those to institutes with 100 times its budget.

OAM's profile is likely to remain high. Next month it will host a consensus conference on acupuncture on the NIH campus in Bethesda, Maryland. 